\title{
A LONGITUDINAL STUDY OF STRESS-BUFFERING EFFECTS FOR URBAN AFRICAN-AMERICAN MALE ADOLESCENT PROBLEM BEHAVIORS AND MENTAL HEALTH
}

\section{Marc A. Zimmerman}

University of Michigan

Jesus Ramirez-Valles

University of Illinois, Chicago

Kinga M. Zapert and Kenneth I. Maton

University of Maryland, Baltimore County

The stress-buffering hypothesis was explored longitudinally in a sample of 173 urban, male, African-American adolescents. Data on parental and friend support, stressful life events, alcohol and substance use, delinquency, and psychological symptoms were collected twice, six months apart. No support for the stress-buffering hypothesis was found for any of the dependent variables. Friend support also was unrelated to the dependent variables longitudinally. Parental support predicted less anxiety and depression longitudinally, but psychological symptoms did not predict increased parental support over time. The findings suggest that parental support may help insulate these African-American youths from anxiety and depression, but that the youths' symptoms do not necessarily activate increased levels of parental support. The results of this study add to the growing body of research that indicates the positive role parental support plays in the healthy development of African-American adolescents. (C) 2000 John Wiley E Sons, Inc.

This research was supported by the National Institute on Drug Abuse, Grant No. RO1DA04766, and the U.S. Department of Justice, Office of Juvenile Justice and Delinquency Prevention, Grant No. 87JNCX0010. Correspondence to: Marc A. Zimmerman, Department of Health Behavior and Health Education, School of Public Health, University of Michigan, Ann Arbor, MI 48109-2029. E-mail: marcz@umich.edu 
Adolescence is regarded as a developmental period associated with a particularly high frequency of potentially stressful life events, including biological changes, environmental transitions, and psychosocial changes in relationships with parents and significant others (Compas, Hinden, \& Gerhardt, 1995; Johnson, 1986; Newcomb, Huba, \& Bentler, 1981; Petersen, 1982; Petersen \& Taylor, 1980). These stressful life events traditionally have been viewed as contributing to adolescent emotional and behavioral problems (Sterling, Cowen, Weissberg, Lotyczewski, \& Boike, 1985). Nevertheless, the inconsistency of the empirical findings on the relationship between stressful events and adolescent problems (Burt, Cohen, \& Bjorck, 1988; Cohen, Burt, \& Bjorck 1987; Swearingen \& Cohen, 1985) has led researchers to explore the variables (e.g., social support) that may moderate the sometimes deleterious effects of stressful life events. This study is an analysis of the role that social support plays in moderating the effects of stress on male AfricanAmerican adolescents' problem behavior and psychological well-being.

A number of researchers have found a positive relationship between stressful life events and adolescent-adjustment problems (Baer, Garmezy, McLaughlin, Pokorny, \& Wernick, 1987; Burt et al., 1988; Compas, Howell, Phares, Williams, \& Guinta, 1989; Forehand et al., 1991). Others, however, have reported that stressful life events are not significant predictors of adolescent problems (Siegel \& Brown, 1988; Swearingen \& Cohen, 1985). When considered cross sectionally, stressful life events likely are to be related to adolescent problem behaviors and distress (Baer et al., 1987; Burt et al., 1988; Forehand et al., 1991). Prospective analyses, however, appear to be less consistent. While some researchers have found support in prospective analyses for the hypothesized positive association between stressful events (acute or chronic) and adolescents' emotional and behavioral problems (Compas, Davis, Forsythe, \& Wagner, 1987; Compas, Orosan, \& Grant, 1993; Towbes, Cohen, \& Glyshaw, 1989; Windle, 1992), others have not (Siegel \& Brown, 1988; Swearingen \& Cohen, 1985). Research on major events indicates a weak prospective association with psychological adjustment (Compas, 1987). A similar weak association is found between accumulated life stress and psychological functioning (Cohen et al., 1987). One reason for these equivocal findings may be that stress does not affect uniformly all adolescents and all of their problems. Social support is one of the variables that has received the most attention as a potential moderating factor in adolescent responses to stressors. Consistent with the literature on social support in adults (Cohen \& Wills, 1985), researchers have used two models to study the role of social support in the adolescent response to stressful events-a main-effects model and an interactive-effects (i.e., buffering) model.

The main-effects model assumes that social support produces a generalized positive effect on individuals regardless of the level of stressful life events. Researchers have reported that low levels of family support tend to be associated with higher levels of problem behaviors, including alcohol and substance use (Brook, Brook, Gordon, Whiteman, \& Cohen, 1990; Maton \& Zimmerman, 1992; Wills, 1986; Windle, 1992), externalizing and internalizing problems (Windle, 1992), and academic problems (Forehand et al., 1991). The evidence for peer social support, however, has been less consistent. Some researchers have indicated that increased levels of peer support are related to higher frequency of substance use problems and delinquent behavior (Jessor \& Jessor, 1977), whereas others have noted that for select subgroups of adolescents (e.g., White highschool students) and specific outcomes (e.g., depression), peer social support may be associated with lower levels of problem behavior or distress (Maton et al., 1996; Windle, 1992). Thus, the precise pattern of main-effect relationships between social support and 
negative outcomes for adolescents may well depend on a number of factors, including source of support (e.g., family adults, nonfamily adults, peers), individual characteristics of an adolescent (e.g., ethnicity, gender, age), and types of problem behaviors evaluated (e.g., externalizing, internalizing).

The stress-buffering model suggests that social support moderates the deleterious effects of high levels of stress (Cohen, 1988; Cohen \& Wills, 1985; House, 1981; Williams \& House, 1991). The statistical interaction between stress and support is used to test the stress-buffering (i.e., moderating) effects of social support. Empirical evidence of the buffering effects of social support for adolescents, however, is limited. The samples included in most studies have consisted of predominantly White, early-to-middle adolescents attending school, and the research designs were predominantly cross sectional (e.g., Baer et al., 1987; Cauce, Hannan, \& Sargeant, 1992; Forehand et al., 1991; Wolchik, Ruehlman, Braver, \& Sandler, 1989). Overall, cross-sectional studies have provided mixed evidence for the stress-buffering hypothesis. The few studies supporting this hypothesis indicate that it only holds for specific adolescent behaviors (e.g., internalizing problems, social competence), specific sources of social support, and high levels of stress.

Few researchers have addressed the stress-buffering hypothesis using prospective designs (e.g., Burt et al., 1988; DuBois, Darling, Meares, \& Kmir, 1994; DuBois, Felner, Brand, Adan, \& Evans, 1992; Windle, 1992). Burt et al. (1988) examined the stress-buffering effects of a supportive-family environment on early adolescents' depression, anxiety, and self-esteem. Although the cross-sectional analyses identified a number of moderating effects for different aspects of family environment, longitudinal analyses did not support the stress-buffering hypothesis. DuBois et al. $(1992,1994)$ also tested the stressbuffering hypothesis in a sample that included $61 \%$ African-American and $39 \%$ White adolescents attending school. They studied major life events, daily hassles, and social support (family, friends, and school adults) on psychological adjustment and academic performance over a two-year period. They found only one moderating effect for school support and major life events. Windle (1992) examined the stress-buffering effects of parent and friend support on alcohol consumption, alcohol problems, delinquent activity, and depressive symptoms among 277 White, predominantly middle-class, adolescent males and females. He found no support for the buffering hypothesis among females and only limited support for it among males. Windle (1992) points out that efforts to generalize his findings to non-White and high-risk adolescents (e.g., school dropouts) are needed.

Researchers have found that African Americans are faced with more stressful events than Whites due to discrimination and their typically lower socioeconomic status (Robinson, 1990). The few researchers who have examined the stress-buffering effects of social support among African-American adult or adolescent samples have reported inconsistent findings (Dubois et al., 1992; Franklin \& Jackson, 1990; Jung \& Khalsa, 1989; Neighbors \& Lumpkin, 1990). Brown and Gary (1987) and Dressler (1985), for example, found opposite results in different samples of African-American adult males. Brown and Gary (1987) reported no stress-buffering effects found for any of the support measures, while Dressler (1985) found that males with higher extended kin support were less affected by stressful events. McCreary, Slavin, and Berry (1996) tested the stress-buffering effects of friend and family support on problem behavior and self-esteem in a cross-sectional sample of African-American adolescents. Their sample consisted of 103 males and $194 \mathrm{fe}-$ males attending a church event at the time of the study, with a mean age of 15.9 years, and enrolled in school. They found buffering effects for friend support on problem behavior and for family support on self-esteem. 
The present study builds on this previous stress-buffering research by studying urban African-American male adolescents, many of whom left school before graduating. This is a vital group to study because they typically are not included in research (Gibbs, 1989). We also extend past research because we investigate longitudinally the stress-buffering effects of friend and family support on stressful life events for alcohol and substance use, delinquent activity, and psychological symptoms. We expect to find direct effects for parental and friend support (direct effects) but do not expect to find support for stress buffering (moderating effects) for parent or friend support. These hypotheses are based on the notion that parents and friends are expected to have effects on outcomes regardless of the levels of stress experienced by the youth in our study. In other words, the effects' support for African-American adolescents is expected to be independent of the stress they may experience.

\section{METHOD}

\section{Research Participants}

The sample consists of 173 African-American male adolescents from Baltimore, Maryland who completed both Time 1 and Time 2 interviews. This represents a $68 \%$ response rate across time (Time 1 sample $=254$ ). Their mean age at Time 1 was 16.8 years (SD $=1.32)$. Sixty-nine percent $(n=119)$ were not attending school at Time 1 . Most of the youths who left school did so in the ninth $(n=43 ; 36 \%)$ and tenth $(n=30 ; 25 \%)$ grades $(\overline{\mathrm{x}}=9.5 ; \mathrm{SD}=1.16)$. At the time of the first interview, youths no longer attending school had been out of school for an average of 9.6 months $(\mathrm{SD}=8.90)$. Sixty-one percent $(n$ $=104$ ) were not attending school at Time 2 (one youth had missing data). Educational attainment of the youths' parents ranged from less than 7th grade to at least some postcollege education. The parent with the highest grade completed was used to indicate parent-education level (32 youth had missing data). Most parents for whom we had data had completed high school $(n=72 ; 51 \%)$ or at least had some college $(n=47 ; 33 \%)$. Seventy-two youths $(42 \%)$ lived in single-mother households, $24(14 \%)$ lived with single mothers and extended family members, 19 (11\%) lived with extended family members only, and $49(28 \%)$ lived with either biological parents or a stepparent. Nine youth $(5 \%)$ had missing family structure data.

\section{Procedure}

Recruitment. Youths were recruited to participate in the study in four ways: (1) mail solicitations of randomly selected youths from school-district dropout lists $(n=58 ; 34 \%)$;

(2) recruitment by peers paid to enlist youths from their neighborhoods $(n=27 ; 15 \%)$;

(3) referrals from community programs such as the Urban League ( $n=64 ; 37 \%)$; and

(4) solicitation through media, posters, and flyers $(n=22 ; 13 \%)$. We obtained access to mailing addresses and rosters of school-district dropouts from school-district administrators. Two cases did not have recruitment information but were included in all analyses that did not involve recruitment effects. Analyses of youths with complete Time 1 and Time 2 data explored differences by recruitment method, which are detailed below.

Data collection. Participants were informed that all information shared with the research team was confidential and legally protected from subpoena. Each was paid $\$ 15$ for an initial 90-minute interview and $\$ 35$ for a second interview, six months later at Time 2. 
Trained interviewers verbally administered structured questionnaires, followed by a series of open-ended questions. Interviews were conducted in private rooms in various community organizations (e.g., church office, Urban League, recreation center). Consent forms from both the youths and their parents (if they were under 18 years of age) were obtained. Nine trained interviewers, African Americans $(n=4)$, Whites $(n=5)$, males $(n=2)$, and females $(n=7)$ carried out the interviews. Analyses did not indicate any effects of interviewer ethnicity or gender on the study variables (Zimmerman \& Maton, 1992).

We were able to estimate only the response rate from the school-district dropout list because the other procedures did not use an identified pool of respondents. Our response rate from the dropout list was only $12 \%$. We decided to use alternative strategies when it became clear that our random-selection procedure did not produce a large enough sample. It is noteworthy that we contacted over $90 \%$ of the youths randomly selected from the list by letter first, then followed up with a telephone call to answer questions, encourage participation, and to schedule an interview. We telephoned all youths again the day before the scheduled appointment to remind them and again to insure confidentiality.

\section{MEASURES}

The means, standard deviations, skewness, and kurtosis for the study variables are presented in Table 1. They are briefly described below.

\section{Alcohol and Marijuana Use}

Youths were asked to rate their frequency of use for alcohol and marijuana over the past six months using a 7-point Likert scale ( 6 was coded as more than once a day, 0 was coded as not at all). A composite alcohol-use variable was developed by summing each youth's frequency ratings for beer, wine, and hard liquor. Scores could range from 0 to 18, with 18 indicating the most use. Marijuana use was measured by a single item. Harder drug use (e.g., cocaine, hallucinogens, pills) was omitted because use was limited in the sample, and the variable was highly skewed. Marijuana-use scores could range from 0 to 6 . The correlation between Time 1 and Time 2 alcohol use was .57. The across-time correlation for marijuana use was .69.

Table 1. Means, Standard Deviations, and Range for All Study Variables

\begin{tabular}{lrrrrr}
\hline & & $\bar{x}$ & SD & Skewness & Kurtosis \\
\hline Alcohol consumption, & Time 1 & 2.00 & 2.41 & 1.55 & 2.28 \\
Alcohol consumption, & Time 2 & 1.79 & 2.45 & 1.84 & 3.41 \\
Marijuana use, & Time 1 & 1.07 & 1.61 & 1.66 & 1.96 \\
Marijuana use, & Time 2 & .84 & 1.61 & 1.98 & .96 \\
Delinquent activity, & Time 1 & 5.56 & 1.48 & .29 & -1.43 \\
Delinquent activity, & Time 2 & 5.41 & 1.47 & 1.26 & -1.23 \\
Depressive symptoms, & Time 1 & 10.88 & 4.37 & 1.77 & 1.70 \\
Depressive symptoms, & Time 2 & 9.77 & 4.49 & 1.25 & 3.20 \\
Anxiety symptoms, & Time 1 & 10.83 & 3.99 & 1.36 & 2.32 \\
Anxiety symptoms, & Time 2 & 10.50 & 3.89 & -.92 & .35 \\
Stressful life events, & Time 1 & 38.64 & 2.60 & -.11 & .43 \\
Parent support, & Time 1 & 42.90 & 10.64 & 7.62 & -.50 \\
Friend support, & Time 1 & 31.46 & & & .43 \\
\hline
\end{tabular}




\section{Delinquency}

Delinquency was measured with four dichotomous items asking youths if they had ever been in trouble with police, been arrested, appeared before a juvenile court, or been incarcerated. Delinquency scores could range from 4 (no delinquency) to 8 (very delinquent). The internal reliability of the 4-item delinquency measure was .79 at both time points, and higher scores on the measure correlated with substance use (Zimmerman \& Maton, 1992). The correlation between Time 1 and Time 2 delinquency measures was .77 .

\section{Anxiety and Depression}

The anxiety and depression subscales of the Brief Symptom Inventory (Derogatis \& Spencer, 1982) were used. Each subscale included six symptoms that were rated on a 5point Likert scale. Scores could range from 6 to 30 (30 indicated the highest level of anxiety and depression). The Cronbach alpha for anxiety was .63 at Time 1 and .68 at Time 2. The Cronbach alpha for depression was .71 at Time 1 and .81 at Time 2. The correlation between Time 1 and Time 2 depression was .46. The across-time correlation for anxiety was .34 .

\section{Social Support}

Social support from parents and friends was assessed using a shortened version of Procidano and Heller's (1983) Parents and Friends Scale, both using a 5-point Likert format. The shortened parental-support scale included 12 items, with a possible range from 12 to 60 (60 indicated the highest level of support). The shortened friend-support scale included 10 items, with a possible range from 10 to 50. The shortened parental-support scale had a Cronbach alpha of .90 at Time 1 and .93 at Time 2. The shortened friendsupport scale had a Cronbach alpha of .80 at Time 1 and .83 at Time 2. The correlations between Time 1 and Time 2 parent and friend support were .66 and .60 , respectively.

\section{Stressful Life Events}

Youths were asked to indicate whether or not they had experienced 35 different stressful life events in the past six months. The 35 items included death of loved ones, illness (mental and physical), injury of family members or friends, and life changes such as moving, sleeping or eating patterns, breaking up with a girlfriend, and parental divorce. Scores could range from 35 to 70 (70 indicated the most stress). The correlation for Time 1 and Time 2 stressful life events was .46. The events listed match those included in the adolescent-life-changes scale (Yeaworth, York, Hussey, Ingle, \& Goodwin, 1980). The Cronbach alpha for this measure was .66 at Time 1 and .55 at Time 2.

\section{Social Desirability}

The social desirability scale from Jackson's Personality Research Form (Jackson, 1967) was used to assess possible response bias at Time 2. The 16-item measure used a true/false format. Scores could range from 0 to16, with high scores indicating socially desirable response bias. The mean score bias was $11.8(\mathrm{SD}=1.94)$. The Cronbach alpha was .53. 


\section{Data Analysis}

Multiple-regression analysis was used to test the stress-buffering model cross sectionally in Year 1 and longitudinally for Year 2. The dependent variables for these analyses were alcohol consumption, marijuana use, delinquent activity, depressive symptoms, and anxiety symptoms. The cross-sectional model included the following entry sequence: parental support, friend support, stressful life events, parental support $\times$ life events, and friend support $\times$ life events. In the longitudinal analysis, the measurement of the dependent variable at Time 1 was entered first, followed by Time 1 parental social support, friend social support, and stressful life events. The final step in the equation included the interaction (multiplicative) terms of stressful life events with parent and friend support. The individual measures of social support and stress events were centered to their respective means to avoid multicollinearity (Aiken \& West, 1991). Regression analyses were conducted using the centered values of parental support, friend support, stressful life events, and the interaction terms of stressful life events with each of the social-support measures. Our first set of analyses examined recruitment, attrition, and family-structure effects on the study variables.

\section{RESULTS}

\section{Recruitment Effects}

Youths recruited by media reported less parental support $(\overline{\mathrm{x}}=38.5 ; \mathrm{SD}=13.18)$ than youths recruited by referrals from community programs $(\overline{\mathrm{x}}=46.2 ; \mathrm{SD}=9.21)[F(3,168)$ $=3.86, p<.05]$. Youths recruited by mail reported more delinquency $(\overline{\mathrm{x}}=5.9 ; \mathrm{SD}=$ 1.63) than youths recruited by referrals from community programs $(\overline{\mathrm{x}}=5.2 ; \mathrm{SD}=1.36)$ $[F(3,167)=2.57, p<.05]$. No other recruitment effects were found.

\section{Attrition Effects}

Youths who completed both interviews reported fewer stressful life events $(\overline{\mathrm{x}}=38.6$; SD $=2.59)$ than youths who completed only the first interview $(\overline{\mathrm{x}}=39.5 ; \mathrm{SD}=2.97)$ $[t(246)=2.26, p<.05]$. Youths who completed both interviews also reported less delinquency $(\overline{\mathrm{x}}=5.56 ; \mathrm{SD}=1.48)$ than youths who completed only the first interview $(\overline{\mathrm{x}}=$ $6.19 ; \mathrm{SD}=1.57)[t(246)=3.05, p<.05]$. No other differences were found for youths who completed Time 1 versus Times 1 and 2 interviews.

\section{Change in Dependent Variables}

Across-time analyses for each dependent variable indicated that youths' depression decreased from Time 1 to Time $2[t(163)=2.74 ; p<.05]$. No across-time differences were found for alcohol $[t(163)=1.46$; ns $]$ or marijuana use $[t(163)=1.77$; ns $]$, delinquency $[t(163)=1.42 ; \mathrm{ns}]$, and anxiety $[t(163)=.56 ; \mathrm{ns}]$.

\section{Cross-Sectional Analyses}

Zero-order correlations among the study variables are presented in Table 2. All the coefficients are in the expected direction. The cross-sectional analyses indicated that less parental support predicted depression and anxiety symptoms but no other outcomes. 


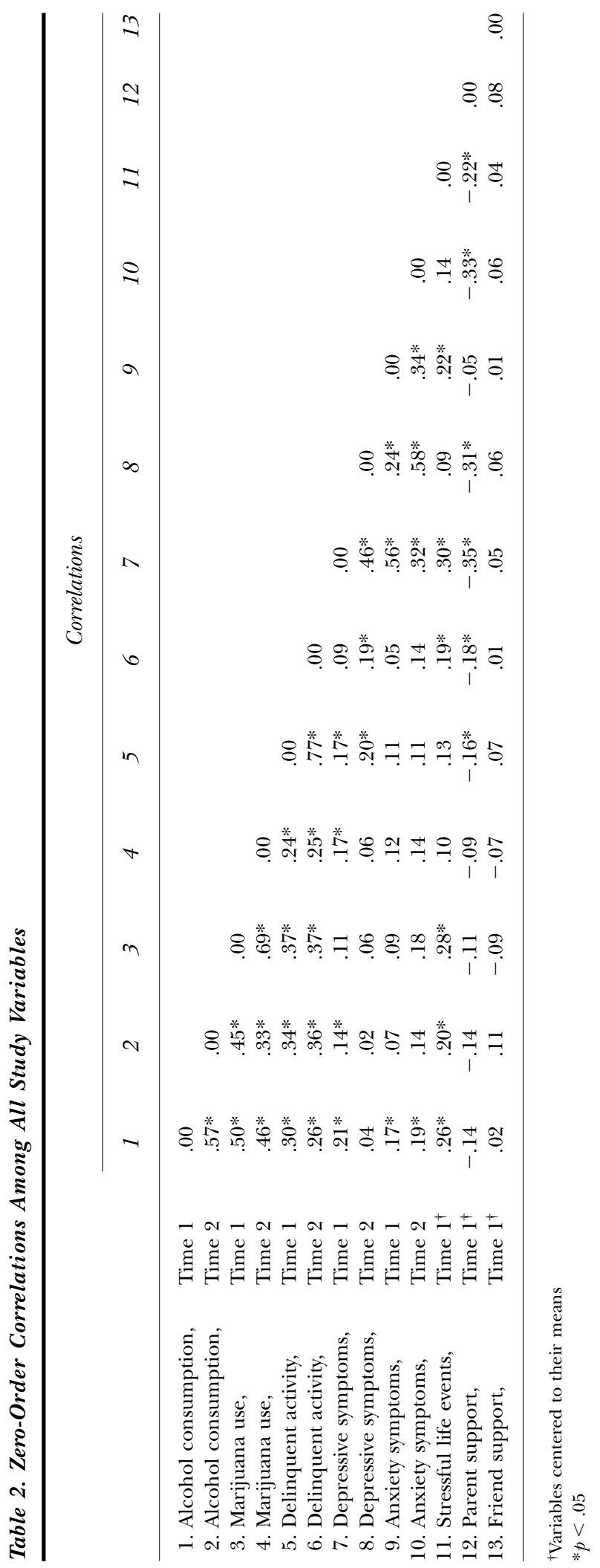


Table 3. Final Betas and Adjusted $\mathbf{R}^{2}$ for Time 1 Cross-Sectional Regression Analyses

\begin{tabular}{llccccc}
\hline & $\begin{array}{c}\text { Parent } \\
\text { Support } \\
(\text { FMS })\end{array}$ & $\begin{array}{c}\text { Friend } \\
\text { Support } \\
(\text { FRS })\end{array}$ & $\begin{array}{c}\text { Stressful } \\
\text { Events } \\
\text { (SE) }\end{array}$ & $\begin{array}{c}\text { FMS } \\
\times\end{array}$ & $\begin{array}{c}\text { FRS } \\
\times\end{array}$ & $\begin{array}{c}\text { Adjusted } \\
\mathrm{R}^{2}\end{array}$ \\
\hline Alcohol Consumption & -.06 & -.00 & $.22^{*}$ & -.15 & -.05 & .07 \\
Marijuana Use & -.03 & -.11 & $.26^{*}$ & -.08 & -.05 & .07 \\
Delinquent Activity & -.14 & .03 & .10 & -.05 & -.15 & .03 \\
Depressive Symptoms & $-.27^{*}$ & -.05 & $.22^{*}$ & $-.16^{*}$ & .01 & .18 \\
Anxiety Symptoms & $-.19^{*}$ & .12 & $.18^{*}$ & .03 & -.02 & .06 \\
\hline
\end{tabular}

$* p<.05$.

Parental support added $12 \%$ of the variance for predicting depression $[F(1,163)=$ $22.11 ; p<.01]$ and $5 \%$ of the variance for predicting anxiety $[F(1,163)=7.78 ; p<.01]$. Stressful life events predicted more alcohol consumption, marijuana use, and depressive and anxiety symptoms. It added $6 \%[F(1,161)=9.92 ; p<.01], 7 \%[F(1,161)=12.11$; $p<.01], 6 \%[F(1,161)=10.97 ; p<.01], 3 \%[F(1,161)=5.31 ; p<.05]$ of the variance, respectively. Friend support did not predict any outcomes. The only interaction effect found was for parent support and stressful events in predicting depressive symptoms. The interaction effect indicated that depression among youths with higher levels of stress was reduced for those with more parental support. The interaction effect added $2 \%$ of the variance in the equation $(F(1,160)=4.68 ; p<.05]$. Table 3 reports final regression weights and adjusted $R^{2}$ for the cross-sectional results.

\section{Longitudinal Analyses}

The results of the longitudinal-regression analyses for alcohol consumption, marijuana use, delinquent activity, depressive symptoms, and anxiety symptoms are presented in Table 4. No interaction effects of stressful life events and parent and friend support were found across all five analyses. Effects for parental support were found for predicting Time 2 depressive symptoms and Time 2 anxiety symptoms. In both cases, parental support inversely was related to symptoms. No effects for friend support were found in any of the analyses. Effects for stressful life events were found for Time 2 marijuana use. Higher levels of stressful events were associated with less marijuana use.

Table 4. Final Betas and Adjusted $\mathbf{R}^{2}$ for Longitudinal-Regression Analyses

Time 1 Predictor Variables

\begin{tabular}{|c|c|c|c|c|c|c|c|}
\hline $\begin{array}{l}\text { Time } 2 \text { Dependent } \\
\text { Variables }\end{array}$ & $\begin{array}{l}\text { Time } 1 \\
\text { Variable }\end{array}$ & $\begin{array}{c}\text { Parent } \\
\text { Support } \\
\text { (FMS) }\end{array}$ & $\begin{array}{l}\text { Friend } \\
\text { Support } \\
\text { (FRS) }\end{array}$ & $\begin{array}{c}\text { Stressful } \\
\text { Events } \\
\quad(S E)\end{array}$ & $\begin{array}{c}F M S \\
\times \\
S E\end{array}$ & $\begin{array}{c}F R S \\
\times \\
S E\end{array}$ & $\begin{array}{c}\text { Adjusted } \\
\mathrm{R}^{2}\end{array}$ \\
\hline Alcohol Consumption & $.52 *$ & -.06 & .09 & .03 & -.13 & -.05 & .33 \\
\hline Marijuana Use & $.70 *$ & -.01 & -.001 & $-.12 *$ & -.11 & .03 & .49 \\
\hline Delinquent Activity & $.77 *$ & -.03 & -.05 & .08 & -.04 & .01 & .61 \\
\hline Depressive Symptoms & $.43 *$ & $-.19 *$ & -.01 & .07 & .07 & .01 & .22 \\
\hline Anxiety Symptoms & $.28 *$ & $-.28 *$ & .06 & .03 & .09 & .02 & .17 \\
\hline
\end{tabular}

$* p<.05$. 
Parental support added $3 \%$ of the variance for predicting depressive symptoms $[F(2$, $162)=5.70 ; p<.01]$ and contributed $7 \%$ of the variance for predicting anxiety symptoms $[F(2,162)=13.56 ; p<.01]$. No other steps in any other regression equation added additional variance to the prediction of the Time 2 dependent variable.

\section{Reciprocal Causation}

We conducted additional regression analyses to explore if Time 1 depression and anxiety predicted Time 2 parental support after controlling for Time 1 parental support. These analyses were conducted to further understand the effects of the support coefficients on psychological symptoms. Additionally, these analyses allow a fuller exploration of the causal link between support and psychological symptoms. Only these variables were used in these analyses because they were the only ones that were significant in the stress-buffering analyses described above. The results indicate that neither depression $[b$ $=-.06 ; t(2,173)=-1.0 ; \mathrm{ns}]$ nor anxiety $[b=-.04 ; t(2,173)=-.68 ; \mathrm{ns}]$ at Time 1 predicted Time 2 parental support.

\section{Additional Analyses}

We also conducted additional analyses to examine if parental education, respondents' school status (Time 1), family structure, and social desirability might explain the results. Parental education was correlated only with anxiety $(r=-.20 ; p<.05)$ but not any other dependent variable in the study. When parental education was included in the first step of the hierarchical regression, it did not predict anxiety in the final equation, and the results for the other variables remained the same.

School status at Time 1 was associated with alcohol use $[t(137.9)=3.99 ; p<.05]$, marijuana use $[t(166.5)=6.12 ; p<.05]$, and delinquency $[t(90.9)=5.13 ; p<.05]$. Youth who left school reported more alcohol and marijuana use and more delinquency than youth who were in school. When school status was included in the first step of the hierarchical regression to predict each of these outcomes, it did not predict any of the outcomes in the final equation, and the results of the other variables remained the same.

Youth from five different household structures (i.e., single mother only, stepparent, both biological parents, mother and extended family, and extended family only) did not differ on any of the study variables. Analyses that included only two family constellations-two parent (stepparent and biological parents), all others-also indicated no differences on any of the study variables. When the two constellation variables were entered in the stress-buffering regression equation, it did not predict any of the outcomes in the final equation. The results for the other predictors in the analysis did not change when family structure was included in the equation.

Finally, we included social desirability in our analyses. Social desirability was not correlated with any of the outcome measures (i.e., none were significant). When we included social desirability in the regression analyses, none of the results changed, and social desirability did not predict any outcomes.

\section{DISCUSSION}

The results of our cross-sectional and longitudinal analyses do not support the stressbuffering hypothesis for social support among urban, male African-American youths. 
Stress-buffering mechanisms, as traditionally defined, using predominantly White, middle-class samples may not be as relevant for urban African-American males. Extended family, for example, may play a vital role in the healthy development of African-American youths (Chatters, Taylor, \& Jayakody, 1994; Farnworth, 1984; Tienda \& Angel, 1982), but as in our study, most tests of the stress-buffering model include only parental and peer support. Researchers have found that informal sources of support and nonkinship relationships help reduce the negative consequences of stress among African-American adolescents (Brown \& Gary, 1987; Neighbors \& Lumpkin, 1990). Nevertheless, our results are similar to those found by Windle (1992), who studied mostly White youths.

Our findings that parent support had a direct effect on psychological symptoms are noteworthy. While these results are not consistent with previous research on White male adolescents (Windle, 1992), they are consistent with other studies of African-American youths (Prendergast, Austin, Maton, \& Baker, 1989; Taylor, 1996). These results suggest that parental support might have a role in alleviating anxiety and depression. Parental support predicted less anxiety and depression concurrently and prospectively. It also is noteworthy that psychological symptoms did not predict increased parental support over time. Parental support may help to insulate these African-American youths from anxiety and depression, but their symptoms necessarily do not activate increased levels of parental support longitudinally. The direct effect of parental support longitudinally supports a compensatory model of resiliency (Zimmerman \& Arunkumar, 1994; Garmezy, Masten, \& Tellegen, 1984). A compensatory factor is a variable that neutralizes the effects of a risk factor. Although we did not find stressful life events to be a risk factor for psychological well-being longitudinally, parent support may be compensating for another risk factor that we did not measure (e.g., susceptibility to peer pressure; racial discrimination).

Our cross-sectional results are consistent with past research (Windle, 1992). Stressful life events were associated concurrently with alcohol and marijuana use and psychological symptoms. We also found parental support had a buffering effect for stressful events for predicting depressive symptoms cross sectionally. Results of the prospective analyses, however, indicate that prior life events do not predict a change in problem behaviors or psychological symptoms. Windle (1992) also found a similar pattern for the concurrent and prospective analyses he conducted. One interpretation of the discrepancy in these findings is that stressful events may have a more immediate effect on adolescents but have only minimal lasting consequences. Nevertheless, the positive effects of parental support in both concurrent and prospective analyses suggest the vital role they play in the healthy development of African-American adolescents. This is consistent with other researchers who have found parental support among African-American adolescents acts to both compensate for and protect against risks they face (Billingsley, 1992; Taylor, 1996; Zimmerman, Salem, \& Notaro, in press; Zimmerman, Steinman, \& Rowe, 1998).

Several limitations of our study, however, should be considered. One interpretation of the results is that the somewhat low scores on the depression and anxiety scales suggest that the sample may be relatively healthy. The depression scores, however, are consistent with past research of adolescents using the CES-D, a 20-item, 0-3 scaled measure of depression. CES-D case criterion is a score of 16 or greater out of a possible score of 60 (27\% of the total). Roberts, Roberts, and Chen (1997) report that eight studies of adolescents using the CES-D found mean scores to range between 16 and 20 (average = 17). The items used in our depression scale are included in the CES-D. Although the two measures cannot be directly compared, it is noteworthy that the mean scores for 
depression in our sample constituted $36 \%$ and $32 \%$ of the total score of our measure in Years 1 and 2, respectively. While comparable anxiety data are not available, the percent of total for our measure is similar to that for depression. It is also noteworthy that the data on ethnic differences in adolescent depression are equivocal (Roberts et al., 1997). The most consistent difference, when it is found, is for Mexican-American youths to be higher compared to White and African-American youths (Roberts \& Sobhan, 1992). Thus, the conclusion that our sample is relatively healthy does not appear to be supported by the data.

The data regarding stressful life events are less comparable across samples due to differences in events listed, time frame for occurrence of the event, and sample characteristics. Our data indicate that the youths in our sample averaged three to four stressful life events in the last six months. It is possible, however, that one reason we did not find stress-buffering effects of social support may be due to the relatively low stress levels reported by the youths in our study. Alternatively, our measure may not have included particularly relevant stressors for urban, male, African-American adolescents, such as issues related to violence (e.g., victimization, fear of injury), living in neighborhoods with high concentrations of poverty, and experiences with racism (Williams \& House, 1991). Several researchers have pointed out that the stress-buffering model is most appropriate under circumstances of high stress (Lacitra-Kleckler \& Wass, 1993; Wheaton, 1985; Williams \& House, 1991; Wolchik et al., 1989). Future research may benefit from including measures of stress that specifically are associated with urban poverty.

Another interpretation of our results is that the use of interview procedures instead of a self-report format may bias the data obtained. We believe, however, that the data are as accurate as self-reported data for several reasons. First, the substance-use rates are similar to those from other studies with a comparable sample (Brunswick, Merzel, \& Messeri, 1985). Second, our interviewer training and procedures were designed to build rapport with youths and assure the quality of the data. Interviewer ratings regarding the validity of the data, for example, suggested that youths were consistent in their responses, understood the questions, and paid attention during the interview. Third, the fact that we did not find interviewer effects for ethnicity or sex provide further confidence that our interviewers did not systematically bias the data. Fourth, we informed the youths that we had subpoena protection from the federal government (i.e., Certificate of Confidentiality) to assure them that the data could not be obtained by the police, courts, their parents, or anyone not involved in the research project. Finally, prior research on this sample indicated that social desirability was not correlated with the study variables (Zimmerman \& Maton, 1992). We chose to use an interview procedure because personal contact was vital for gaining the cooperation of the young men who participated in the study. Nevertheless, future research may benefit from several additional strategies to insure the validity of the data, including information from significant others (e.g., friends, parents, siblings) and incorporation of a self-report component of the interview for the most sensitive information (e.g., drug use, sexual behavior).

Recruitment effects pose another limitation of the study. The sample was not selected randomly, and we did find recruitment type was related to delinquency and parent support. Recruitment effects, however, only partially influenced our results because only one dependent variable was related to recruitment strategy, and the effect was not large. Youths recruited by media strategies also reported more parental support, but this only included 22 youths. These recruitment-effect analyses, however, included 5 different comparisons across four groups. We would, therefore, expect at least one compari- 
son to be significant by chance alone using a $95 \%$ confidence interval. It is noteworthy that no recruitment effects would be indicated if we used a Bonferroni correction for our $p$ level. Nevertheless, the youths in the study are difficult to sample systematically, so alternative sampling procedures are necessary. This makes it virtually impossible to obtain a sample that represents confidently this population of youth. While our sampling strategy may limit the generalizability of our findings, our sample is a vital group to study because urban, African-American male adolescents are the least effectively addressed adolescent populations in service delivery and social policy (Gibbs, 1984; Zimmerman, Salem, \& Maton, 1995). Although the limitations of this study should not be ignored in interpreting and applying these results, issues for urban African-American males who have dropped out of high school should also not be neglected because sampling them precisely may not be possible.

Our attrition effects also may somewhat limit generalizability. The fact that youths with only Time 1 data reported more stress and less delinquency at Time 1 may explain why effects were not found for these variables. The fact that similar results were found for variables that did not differ between youths who completed both interviews versus Time 1 interviews somewhat mitigates this concern. The sample limitations, however, may raise some concerns regarding restricted range in our data. We do not think this is an adequate explanation of our results for several reasons. First, the descriptive statistics of the data suggest ample variance in the study variables. Second, we have found many theoretically relevant relationships in these data in studies of the risk-protective effects of sociopolitical control (Zimmerman, Ramirez-Valles, \& Maton, in press), the role of fathers in these youths' lives (Zimmerman, Salem, \& Maton, 1995), and psychosocial predictors of substance use (Maton \& Zimmerman, 1992, Zimmerman \& Maton, 1992). It also is noteworthy that, in the current study, we had enough variance in the variables to find main effects for parental support prospectively and for stressful life events concurrently. Third, the cross-sectional and longitudinal samples were large enough to detect moderate-to-small effects (i.e., ample statistical power). Finally, our results are consistent with past research with more systematically sampled, albeit mostly White, adolescents.

The finding that stressful events were associated with less marijuana use was somewhat surprising and inconsistent with previous research. One explanation for this finding may be that the life-events measure may not represent relevant stressors for the youth in our sample. Thus, experiencing more of them may not have the effects on marijuana use that typically are expected. Another explanation of this finding is that the youth in our sample do not use substances as a response to stress. Bachman et al. (1991) found in a national sample of adolescents that African-American youth report lower levels of substance use than White youth. Their overall lower level of use also may reduce the likelihood that they use marijuana when experiencing stress. The fact that social desirability was not associated with any outcome variables, including marijuana use, suggests that response bias may not have influenced the negative correlation between life events and marijuana use. This especially is pertinent because marijuana use is sensitive in nature and was assessed by self-report methodology.

The additional analyses we conducted help to mitigate further concerns raised by some of the study limitations and contribute to the overall confidence in the results. The lack of effects for parental education, school status, and family structure in both bivariate and the stress-buffering models suggest that these factors may not represent alternative explanations of the data. It is significant that parent education was not associated with outcomes in the study because it may be a proxy for socioeconomic status (SES). 
The results of these additional analyses (including social desirability) suggest that parental support is a robust predictor of psychological symptoms in this sample.

Our findings support those of others who found either no or only limited stressbuffering effects among African-American adolescents (Brown \& Gary, 1987; McCreary et al., 1996). It is possible that the stress-buffering hypothesis may need some revision for different contexts and populations. Alternatively, more relevant measures than typically used may need to be included in order to test appropriately stress-buffering mechanisms. Our study suggests that the operationalization of concepts in the stress-buffering model may need to be tailored more specifically for different contexts and populations. The life experience and social status of urban, male African Americans may, for example, require stress to reflect economic strain and racial discrimination (Gary, 1985; Slavin, Rainer, McCreary, \& Gowda, 1991). It also may be beneficial to include assessment of support from extended and fictive kin (Chatters et al., 1994; Dressler, 1985; McAdoo, 1988). Franklin and Jackson (1990) suggest that researchers may benefit from examining factors that contribute to positive mental health among African Americans instead of focusing on psychopathology. The results of this study suggest that parental support may be influential for African-American mental health independent of the stress they may experience. This finding adds to the growing body of evidence that demonstrates the positive role parental support plays in the healthy development of African-American youth.

\section{REFERENCES}

Aiken, L.S., \& West, S.G. (1991). Multiple regression: Testing and interpreting interactions. Newbury Park, CA: Sage.

Bachman, J.G., Wallace Jr., J.M., O’Malley, P.M., Johnston, L.D., Kurth, C.L., \& Neighbors, H.W. (1991). Racial/ethnic differences in smoking, drinking, and illicit drug use among american high school seniors, 1976-1989. American Journal of Public Health, 81, 372-377.

Baer, P.E., Garmezy, L.B., McLaughlin, R.J., Pokorny, A.D., \& Wernick, M.J. (1987). Stress, coping, family conflict, and adolescent alcohol use. Journal of Behavioral Medicine, 10, 449-466.

Billingsley, A. (1992). Climbing Jacob's ladder: The enduring legacy of african-american families. New York: Simon \& Schuster.

Brook, J.S., Brook, D.W., Gordon, A.S., Whiteman, M., \& Cohen, P. (1990). The psychosocial etiology of adolescent drug use: A family interactional approach. Psychology Monographs, 116, 111-267.

Brown, D., \& Gary, L. (1987). Stressful life events, social support networks and the physical and mental health of urban black adults. Journal of Human Stress, 13, 165-174.

Brunswick, A.F., Merzel, C.R., \& Messeri, P.A. (1985). Drug use initiation among urban black youth: A seven year follow-up of developmental and secular influences. Youth and Society, 17, 189216.

Burt, C.E., Cohen, L.H., \& Bjorck, J.P. (1988). Perceived family environment as a moderator of young adolescents' life stress adjustment. American Journal of Community Psychology, 16, 101122.

Cauce, A.M., Hannan, K., \& Sargeant, M. (1992). Life stress, social support, and locus of control during early adolescence: Interactive effects. American Journal of Community Psychology, 20, 787-798.

Chatters, L.M., Taylor, R.J., \& Jayakody, R. (1994). Fictive kinship relations in black extended families. Journal of Comparative Family Studies, 25, 297-313.

Cohen, S. (1988). Psychological models of the role of social support in the etiology of physical disease. Health Psychology, 7, 269-297. 
Cohen, L., Burt, C., \& Bjorck, J. (1987). Life stress and adjustment: Effects of life events experienced by young adolescents and their parents. Developmental Psychology, 23, 583-592.

Cohen, S., \& Wills, T.A. (1985). Stress, social support, and the buffering hypothesis. Psychological Bulletin, 98, 310-357.

Compas, B.E. (1987). Stress and life events during childhood and adolescence. Clinical Psychology Review, 7, 275-302.

Compas, B.E., Davis, G.E., Forsythe, C.J., \& Wagner, B.M. (1987). Assessment of major and daily stressful events during adolescence: The adolescent perceived events scale. Journal of Consulting and Clinical Psychology, 55, 534-541.

Compas, B.E., Hinden, B., \& Gerhardt, C. (1995). Adolescent development: Pathways and processes of risk and resilience. Annual Review of Psychology, 46, 265-293.

Compas, B.E., Howell, D.C., Phares, V., Williams, R.A., \& Guinta, C.T. (1989). Risk factors for emotional/behavioral problems in young adolescents: A prospective analysis of adolescent and parental stress and symptoms. Journal of Consulting and Clinical Psychology, 57, 732-740.

Compas, B., Orosan, P., \& Grant, K. (1993). Adolescent stress and coping: Implications for psychopathology during adolescence. Journal of Adolescence, 16, 331-349.

Derogatis, L.R., \& Spencer, P.M. (1982). The Brief Symptom Inventory (BSI): Administration scoring, and procedures manual-I. Baltimore, MD: Johns Hopkins University School of Medicine, Division of Medical Psychology.

Dressler, W. (1985). Extended family relationships, social support and mental health in a southern black community. Journal of Health and Social Behavior, 26, 39-48.

DuBois, D., Darling, N., Meares, H., \& Kmir, M. (1994). A prospective investigation of the effects of socioeconomic disadvantage, life stress and social support on early adolescence adjustment. Journal of Abnormal Psychology, 103, 511-522.

DuBois, D., Felner, R., Brand, S., Adan, A., \& Evans, E. (1992). A prospective study of life stress, social support, and adaptation in early adolescence. Child Development, 63, 542-557.

Farnworth, M. (1984). Family structure, family attributes, and delinquency in a sample of low-income, minority males and females. Journal of Youth and Adolescence, 13, 349-364.

Forehand, R., Wierson, M., McCombs Thomas, A., Armistead, L., Kempton, T., \& Neighbors, B. (1991). The role of family stressors and parent relationships on adolescent functioning. Journal of American Academy of Child and Adolescent Psychiatry, 30, 316-322.

Franklin, A.J., \& Jackson, J.S. (1990). Factors contributing to positive mental health among black americans. In D. Ruiz (Ed.), Handbook of mental health and mental disorder among black americans (pp. 292-307). Westport, CT: Greenwood Press.

Garmezy, N., Masten, A.S., \& Tellegen, A. (1984). The study of stress and competence in children: A building block of developmental psychopathology. Child Development, 55, 97-111.

Gary, L.E. (1985). Correlates of depressive symptoms among a select population of black men. American Journal of Public Health, 75, 1220-1222.

Gibbs, J.T. (1984). Black adolescents and youth: An endangered species. American Journal of Orthopsychiatry, 54, 6-21.

Gibbs, J.T. (1989). Black american adolescents. In J.T. Gibbs, L.N. Huang \& Associates (Eds.), Children of color: Psychological interventions with minority youth (pp. 179-223). San Francisco: Jossey-Bass.

House, J.S. (1981). Work stress and social support. Reading, MA: Addison-Wesley.

Jackson, D.N. (1967). Personality research form manual. Goshen, NY: Research Psychologists Press.

Jessor, R., \& Jessor, S.L. (1977). Problem behavior and psychosocial development: A longitudinal study of youth. San Diego, CA: Academic Press.

Johnson, J.H. (1986). Life events as stressors in childhood and adolescence. Newbury Park, CA: Sage. 
Jung, J., \& Khalsa, H.K. (1989). The relationship of daily hassles, social support, and coping to depression in black and white students. Journal of General Psychology, 11(6), 407-417.

Lacitra-Kleckler, D.M., \& Wass, G.A. (1993). Perceived social support among high-stress adolescents: The role of peers and family. Journal of Adolescent Research, 8, 381-402.

Maton, K.I., Teti, D.M., Corns, K.M., Vieira-Backer, C.C., Lavine, J.R., Gouze, K.R., \& Keating, D.P. (1996). Cultural specificity of support sources, correlates and contexts: Three studies of africanamerican and caucasian youth. American Journal of Community Psychology, 24, 551-587.

Maton, K.I., \& Zimmerman, M.A. (1992). Psychosocial predictors of substance use among urban black male adolescents. Drugs and Society, 6, 79-113.

McAdoo, H.P. (1988). Black families. Newbury Park, CA: Sage.

McCreary, M.L., Slavin, L.A., \& Berry, E.J. (1996). Predicting problem behavior and self-esteem among african american adolescents. Journal of Adolescent Research, 11, 216-234.

Neighbors, W., \& Lumpkin, S. (1990). The epidemiology of mental disorder in the black population. In D. Ruiz (Ed.), Handbook of mental health and mental disorders among black americans (pp. 55-70). Westport, CT: Greenwood Press.

Newcomb, M.D., Huba, G.J., \& Bentler, P.M. (1981). A multidimensional assessment of stressful life events among adolescents: Derivation and correlates. Journal of Health and Social Behavior, 22, $400-415$.

Petersen, A. (1982). Adolescents and stress. In L. Golberger \& S. Breznitz (Eds.), Handbook of stress: Theoretical and clinical aspects. New York: Free Press.

Petersen, A., \& Taylor, B. (1980). The biological approach to adolescence: Biological change and psychological adaptation. In J. Adelson (Ed.), Handbook of adolescent psychology. New York: Wiley.

Prendergast, M.L., Austin, G.A., Maton, K.I., \& Baker, R. (1989). Substance abuse among black youth. Prevention Research Update 4, Fall. Portland, OR; Los Alamitos and San Francisco, CA: Western Center for Drug-Free Schools and Communities.

Procidano, M.E., \& Heller, K. (1983). Measures of perceived social support from friends and from family: Three validation studies. American Journal of Community Psychology, 11, 1-24.

Roberts, R.E., Roberts, C.R., \& Chen, Y.R. (1997). Ethnocultural differences in prevalence of adolescent depression. American Journal of Community Psychology, 25, 95-110.

Roberts, R.E., \& Sobhan, M. (1992). Symptoms of depression in adolescence: A comparison of anglo, african, and hispanic americans. Journal of Youth and Adolescence, 21, 639-651.

Robinson, D. (1990). Depression among Blacks: An epidemiological perspective. In D. Ruiz (Ed.), Handbook of mental health and mental disorders among black americans (pp. 71-94). Westport, CT: Greenwood Press.

Siegel, J.M., \& Brown, J.D. (1988). A prospective study of stressful circumstances, illness symptoms, and depressed mood among adolescents. Developmental Psychology, 24, 715-721.

Slavin, L.A., Rainer, K.L., McCreary, M.L., \& Gowda, K.K. (1991). Toward a multicultural model of the stress process. Journal of Counseling and Development, 70, 156-163.

Sterling, S., Cowen, E.L., Weissberg, R.P., Lotyczewski, B., \& Boike, M. (1985). Recent stressful events and young children's school adjustment. American Journal of Community Psychology, 13, 87-98.

Swearingen, E.M., \& Cohen, L.H. (1985). Life events and psychological distress: A prospective study of young adolescents. Developmental Psychology, 6, 1045-1054.

Taylor, R.D. (1996). Adolescents' perceptions of kinship support and family management practices: Association with adolescent adjustment in african-american families. Developmental Psychology, 32, 687-695.

Tienda, M., \& Angel, R. (1982). Headship and household composition among blacks, hispanics, and other whites. Social Forces, 61, 508-531. 
Towbes, L.C., Cohen, L.H., \& Glyshaw, K. (1989). Instrumentality as a life-stress moderator for early versus middle adolescents. Journal of Personality and Social Psychology, 1, 109-119.

Wheaton B. (1985). Models for the stress-buffering functions of coping resources. Journal of Health and Social Behavior, 26, 352-364.

Williams, D., \& House J. (1991). Stress, social support, control and coping: A social epidemiological view. In I. Kickbusch \& B. Bandura (Eds.), An introduction to health promotion research. World Health Organization, Geneva, Switzerland.

Wills, T.A. (1986). Stress and coping in early adolescence: Relationship to substance abuse in urban school samples. Health Psychology, 18, 383-406.

Windle, M. (1992). A longitudinal study of stress buffering for adolescent problem behaviors. Developmental Psychology, 28, 522-530.

Wolchik, S.A., Ruehlman, L.S., Braver, S.L., \& Sandler, I.N. (1989). Social support of children of divorce: Direct and stress-buffering effects. American Journal of Community Psychology, 17, $485-501$.

Yeaworth, R.C., York, J., Hussey, M.A., Ingle, M.E., \& Goodwin, T. (1980). The development of an adolescent life change event scale. Adolescence, 15, 91-97.

Zimmerman, M.A., \& Arunkumar, R. (1994). Resiliency research: Implications for schools and policy. Social Policy Report, 8, 1-18.

Zimmerman, M.A., \& Maton, K.I. (1992). Lifestyle and substance use among male african-american urban adolescents: A cluster analytic approach. American Journal of Community Psychology, 20, 121-138.

Zimmerman, M.A., Ramirez-Valles, J., \& Maton, K.I. (in press). Resilience among urban africanamerican male adolescents: A study of the protective effects of sociopolitical control on their mental health. American Journal of Community Psychology.

Zimmerman, M.A., Salem, D.A., \& Maton, K.I. (1995). Family structure and psychosocial correlates among urban african-american adolescent males. Child Development, 66, 1598-1613.

Zimmerman, M.A., Salem, D.A., \& Notaro, P.C. (in press). Make room for daddy II: The positive effects of fathers' role in adolescent development. In R. Taylor \& L. Wang (Eds.), Resilience across contexts: Family, work, culture, and community. Mahwah, NJ: Lawrence Erlbaum Associates, Inc.

Zimmerman, M.A., Steinman, K., \& Rowe, K. (1998). Violence among urban african-american adolescents: The protective effects of parental support. In X.B. Arriaga \& S. Oskamp (Eds.), Addressing community problems: Psychological research and intervention (pp. 78-103). Thousand Oaks, CA: Sage. 